\title{
Analysis of loess landslide mechanism and numerical simulation stabilization on the Loess Plateau in Central China
}

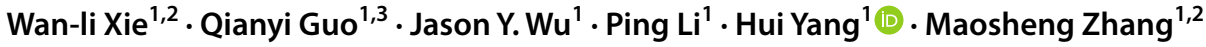

Received: 26 July 2020 / Accepted: 22 December 2020 / Published online: 15 January 2021

(c) The Author(s) 2021

\begin{abstract}
Loess landslides have complicated deformation mechanisms. Accurately describing the internal failure deformation of loess landslides and establishing a theoretical method of landslide instability evaluation for the prevention of subsequent landslides have become important topics in western development project construction in China. This paper presents a case study of the Zhonglou Mountain landslide in Shaanxi Province, China. Based on field investigation results, a two-dimensional stability analysis model was constructed using the finite element method. Taking the deformation characteristics of the landslide as the research basis, the distribution laws of the displacement, stress, and shear strain of this landslide were identified with the strength reduction finite element numerical simulation method. Additionally, the safety factor was evaluated under normal and storm conditions. The numerical simulation results show that the horizontal tensile stress of the landslide was mainly distributed in the middle and upper parts of the landslide under normal conditions, while the vertical tensile stress was distributed near the sliding surface. Under heavy rainfall, the sliding force increased, and the anti-sliding force and anti-sliding section decreased; the location of the maximum shear strain shifted down from the middle and upper parts of the landslide body to the area with a shear crack, and the plastic shear strain area expanded along nearly the entire the sliding surface, leading to the occurrence of a landslide. Thus, the use of anti-slide piles to stabilize the landslide was proposed and tested. Monitoring points were arranged along the sliding surface to evaluate the displacement, stress, and strain responses. The on-site observation results agreed with the modeling results. The use of anti-slide piles was demonstrated to be an effective stabilization method for the Zhonglou Mountain landslide.
\end{abstract}

Keywords Loess landslide $\cdot$ Failure mechanism $\cdot$ Safety factor $\cdot$ Anti-slide pile $\cdot$ Landslide stabilization

Qianyi Guo

g15291855192@163.com

$\triangle$ Hui Yang

huiyang@stumail.nwu.edu.cn

Extended author information available on the last page of the article 


\section{Introduction}

Loess is an aeolian sediment formed by the accumulation of fine sand, silt, and clay deposits in arid and semiarid regions. In China, loess covers an area of approximately $640,000 \mathrm{~km}^{2}$, which is equivalent to approximately $4.4 \%$ of the total land area of China. The Loess Plateau is located in the upper and middle reaches of the Yellow River and has an area of approximately $317,000 \mathrm{~km}^{2}$, which represents the majority of the bulk accumulation of loess worldwide (Zhuang et al. 2018; Li et al. 2018); additionally, approximately 300 million people live in the Loess Plateau region (Peng et al. 2016). The structure of the present-day loess is a result of long-term deposition and loessification, which has led to the formation of typical loess landforms with numerous intensively incised vertical or nearvertical ravines (Li 2018). These ravines are predominantly composed of weakly cemented, silt-sized particles arranged in a metastable, highly porous structure (Hailong and Xie 2015; Xie et al. 2018a; Li et al. 2019) and are highly susceptible to erosion by flowing water and extensive irrigation (Zhang et al. 2013; Xu et al. 2011), and loess landslides frequently occur owing to this water sensitivity (Xu et al. 2018; Li et al. 2016; Xie et al. 2018b; Derbyshire 2001; Dijkstra et al. 1994). Such situations have extensively jeopardized lives and property in the area and have also adversely affected the stability of numerous types of infrastructures. Zhuang et al. (2018) reported that each year, approximately onethird of the geohazards in China occur on the Loess Plateau, resulting in the loss of human life and damage to infrastructure facilities.

The stabilization of loess slopes remains a key issue in geotechnical engineering, particularly in China. To ensure a safe engineering environment in the loess region, studies have been conducted to evaluate the loess landslide mechanisms, thereby establishing effective prevention and mitigation measures to combat loess instability (Qiu et al. 2016). Chen et al. (2019a, b) studied the effects of internal seepage and other parameters on landfill stability and subsequently proposed two failure modes. Crawford et al. (2019a, b) proposed a constitutive equation that can be applied to dynamic hydrological monitoring for landslide detection and verified its feasibility. Rainfall plays an important role in loess slope failure. Wei et al. (2019) proposed a model for estimating the rainfall threshold of a deep-seated landslide based on the genetic algorithm-back-propagation neural network (GA-BPNN) and the genetic algorithm-support vector machine (GA-SVM) methods. To optimize the design scheme for landslide prevention and mitigation, Zhang et al. (2015) conducted a series of centrifuge model tests to investigate the behaviors and mechanisms of slope failure, considering soil behavior, slope inclination, and loading condition parameters. Xu et al. (2018) conducted a reliability analysis on slopes reinforced with piles and concluded that the stabilizing piles should intersect with all the representative slip surfaces with significant failure probabilities to maximize the slope stabilization effectiveness. They evaluated unfavorable site conditions and potential construction weaknesses and studied critical construction procedures and variables, ultimately developing a final optimal implementation scheme for a project.

Stability analysis is the basis of landslide control engineering. At present, the methods used for slope stability analysis primarily include the conventional limit equilibrium approach based on the rigid body limit equilibrium theory and modern numerical analysis techniques such as the finite element method (FEM) (Liu et al. 2015; Agam et al. 2016). The conventional limit equilibrium method currently plays a leading role in landslide stability analysis because it generally provides an acceptable safety factor (SF) in a relatively fast and low-cost manner and with a clear physical meaning. However, as indicated 
by Adhikary and Dyskin (2007), the limit equilibrium method considers rock and soil as rigid bodies, and it does not consider the stress-strain relationship of the soil and the coupled deformation of the soil structure. Therefore, it cannot accurately represent the interaction between loess soil and retaining structures, which limits its application, particularly in the analysis of large landslides (Zheng et al. 2018). The FEM offers a unique advantage because it considers the elastoplastic constitutive relation of soil and the influence of deformation on landslide stability. The stress and strain distribution in a sliding body and the influence of retaining structures on slope deformation and stability can be reasonably obtained with this method (Feng et al. 2017; Alemdag et al. 2015). Although loess landslides have often been reported, their failure mechanisms and mitigation measures have not been thoroughly studied using a numerical approach. In this paper, a case study of the Zhonglou Mountain loess landslide in Qingjian County of Yulin, Shaanxi Province, China (Fig. 1), is presented. Based on the results of our field investigation, a two-dimensional stability analysis model of the landslide was developed using finite element analysis. The stability of the studied landslide before and after remediation was comprehensively studied under normal and storm conditions. The SF values were derived using a strength reduction method, and based on the analysis, the corresponding remediated retaining structure
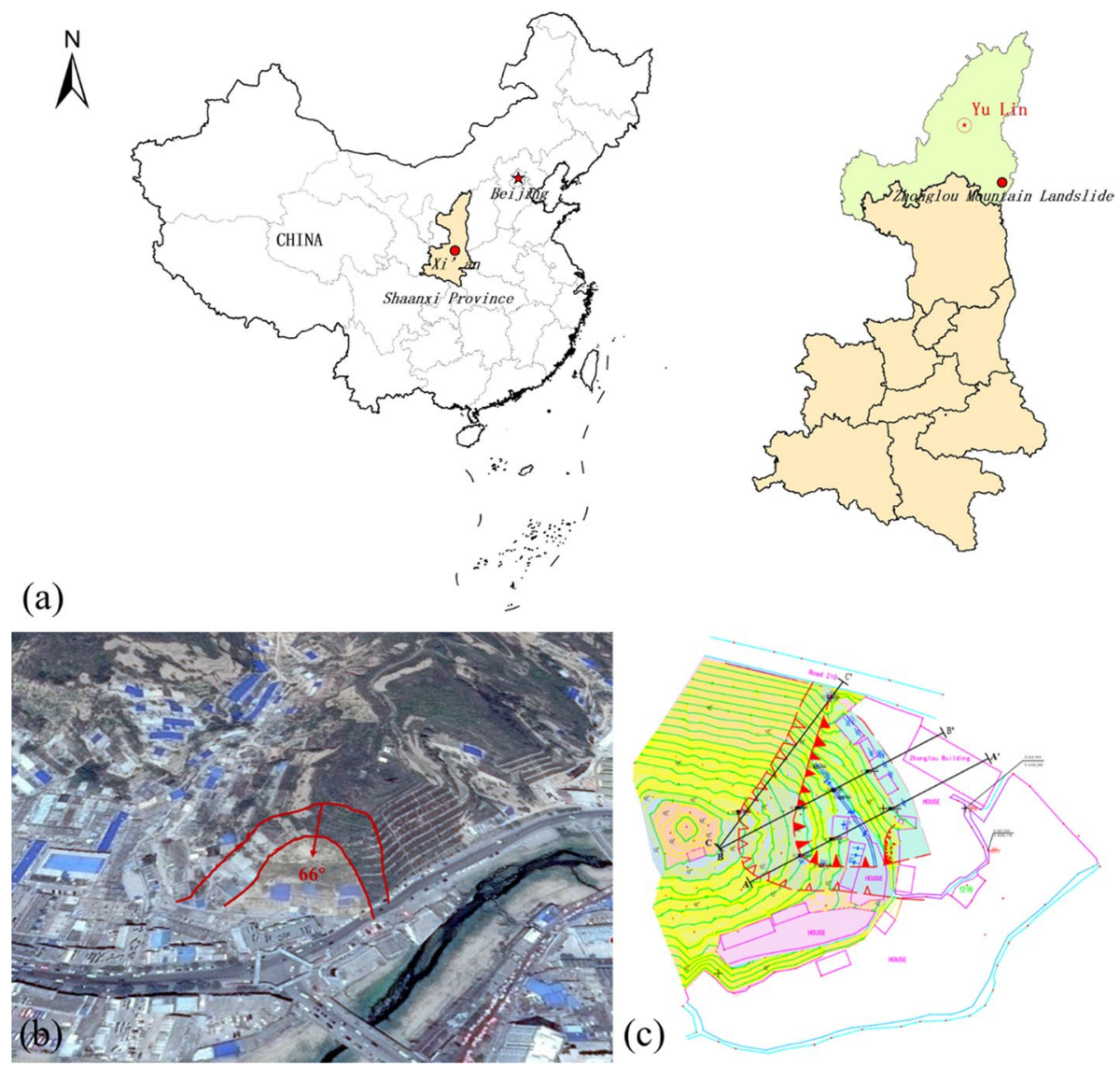

Fig. 1 The geographical position and plane form of Zhonglou Mountain landslide 
was analyzed in detail under different conditions. Moreover, the relations between the supporting structure and the stress, strain, and deformation of the loess slope were accurately evaluated.

\section{Background}

The reported landslide occurred in July 2013 as a result of heavy rainfall. As illustrated in Figs. 1 and 2, the basal surface of the landslide was concave, and the landslide occurred on a southeast-facing slope and was approximately $80 \mathrm{~m}$ wide, $50 \mathrm{~m}$ deep, and $110 \mathrm{~m}$ long, thereby mobilizing a total volume of approximately $3.5 \times 10^{3} \mathrm{~m}^{3}$. The dip direction of the landslide was $62^{\circ} \mathrm{SE}$. According to Zhuang et al. (2018), the landslide examined in this study appeared to follow a typical pattern commonly found on the Loess Plateau. As illustrated in Fig. 2, section A-A' of the landslide was selected as the typical section for analysis. A site survey indicated that the collapsed material consisted of yellowish gray and yellow soil and was mainly composed of Quaternary loess and Triassic siltstone, while the rupture surface was identified in the loess layer. Its upper part was found to be upper Pleistocene aeolian loess, mainly silt and silty clay with vertical joints. Furthermore, the lower part of the landslide was found to be composed of Hujiacun plutonium siltstone of the Upper Triassic $\left(\mathrm{T}_{3} \mathrm{fc}\right)$. The Upper Triassic lithology is dark purple, grayish green/light red layered feldspar sandstone and muddy siltstone. The surface of the site has eroded significantly, resulting in the formation of numerous ravines and sinkholes. Transverse tension cracks and radial shear deformation were identified in the depletion zone, distributed vertically throughout this zone. Moreover, the failure deformation characteristics and borehole information of the Zhonglou Mountain landslide are shown in Fig. 3, including the characteristics of the back edge, the tensile cracks caused by the landslide, and the shear cracks.

The information obtained from borehole ZK1, the test pit, and the exposed shearing zone revealed that the thickness of the eroded mass was approximately 15.5-17.5 m, and the soil structure appeared to be highly disturbed by folding and fracturing. Site

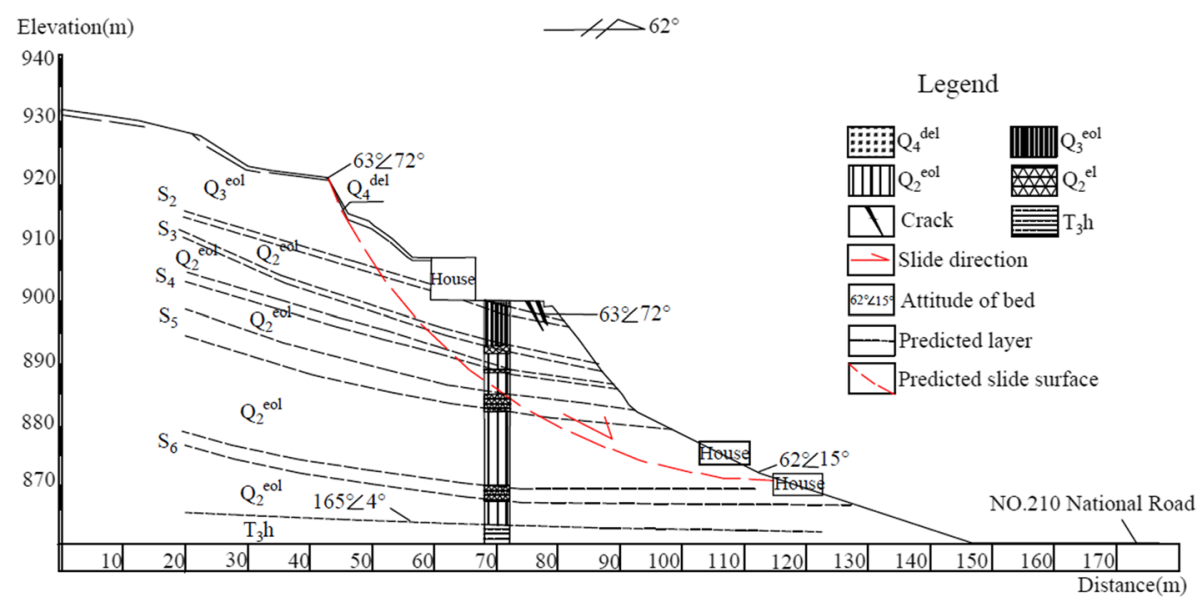

Fig. 2 Geological profile of section A-A' 


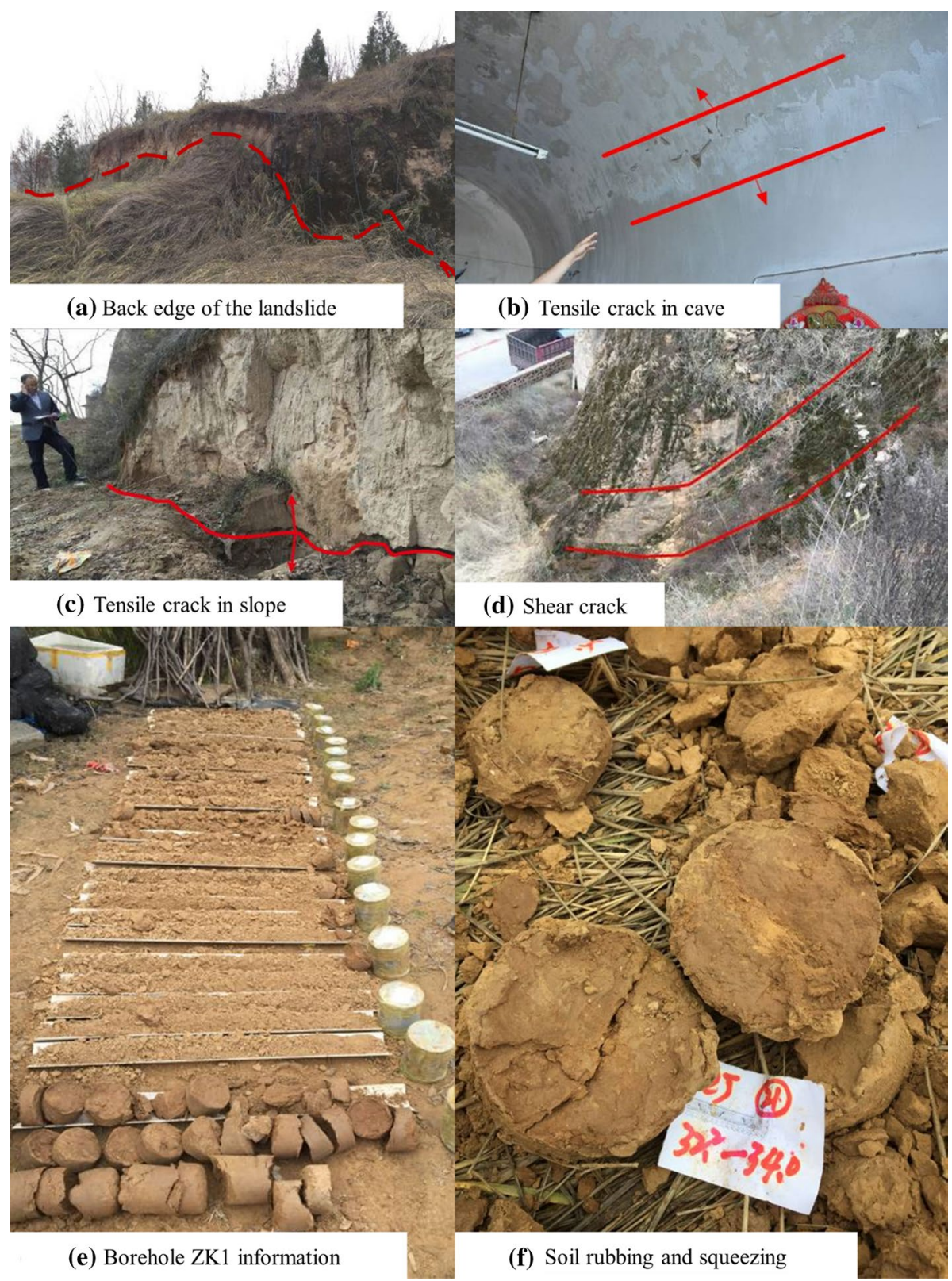

Fig. 3 Failure deformation characteristics and borehole information of the landslide

observations indicated that the landslide was highly correlated with the occurrence of heavy rainfall, which is indicative of the important role that water plays in the evolution of landslide deformation and failure. Rainfall is a common triggering factor for landslides in most loess areas. On the Loess Plateau, concave surfaces are particularly susceptible to the 
occurrence of shallow landslides (Zhuang et al. 2018). The occurrence of sliding can be attributed to the concurrent effects of gravity and hydrostatic pressure.

\section{Finite element modeling}

The failure mechanism and treatment measures were studied using Midas GTS, which is a finite element program. Based on a careful review of site conditions, slope cutting combined with the use of anti-slide piles was selected for treating the landslide. The use of piles to stabilize active slope failure has become one of the most common slope stabilization techniques in recent decades (Ardalan and Ashour 2013). However, owing to the site constraints associated with the local residences and their occupants, only a limited amount of the slope near the head area was removed to reduce the sliding mass weight. The antislide piles were installed at locations in which the maximum shear strain was observed. They penetrated through the slip plane and were embedded in the bedrock to achieve the maximum sliding resistance. As illustrated in Fig. 4, Midas GTS was used to analyze section $\mathrm{A}-\mathrm{A}^{\prime}$ as a representative area to develop a model for the analyses. The boundary conditions included the restraint of the horizontal displacement on both sides of the slope, while the horizontal and vertical displacements were restrained at the bottom of the slope.

The processes that occurred at the site were simulated step by step, namely the transition from initial landslide conditions (original slope) to those for the treated slope (a cut slope with anti-slide piles). Both normal and storm conditions were studied using a strength reduction method. The SF values were derived for each case, and the stress-strain distributions and slope stability variations before and after treatment were examined. The relation between the anti-slide piles and landslide deformation was evaluated effectively and accurately.

The soil mass was analyzed using the Mohr-Coulomb model. This linear elastic, perfectly plastic model requires five basic input soil parameters: Young's modulus $(E)$, Poisson's ratio $(\mu)$, cohesion $(c)$, friction angle $(\varphi)$, and unit weight $(\gamma)$. According to the stratigraphy observed at the site, six different material types were identified. Table 1 displays their properties based on the laboratory investigation results. Moreover, because numerous ruptures can be observed in the slope, soils lying $50 \mathrm{~cm}$ below the surface and the slip zone were considered to be saturated under storm conditions.

To analyze the behavior of the piles and the pile-soil interface, an anti-slide pile was simulated using elastic material and discretized as a beam element, while the contact between the pile and soil was considered to be a frictional interface. In this study, the antislide pile was designed with a rectangular section with a width and length of 3 and $27 \mathrm{~m}$, respectively, and the piles were placed $4 \mathrm{~m}$ apart. The parameters for the pile analysis collected from a previous design are also presented in Table 1.

\section{Results and discussion}

\subsection{SF}

The SF values for the target slope before and after treatment under different stress levels and normal and storm conditions were 1.06 and 0.74 , respectively. The simulations indicated that the slope stability was marginal under its own weight. Complete sliding was 


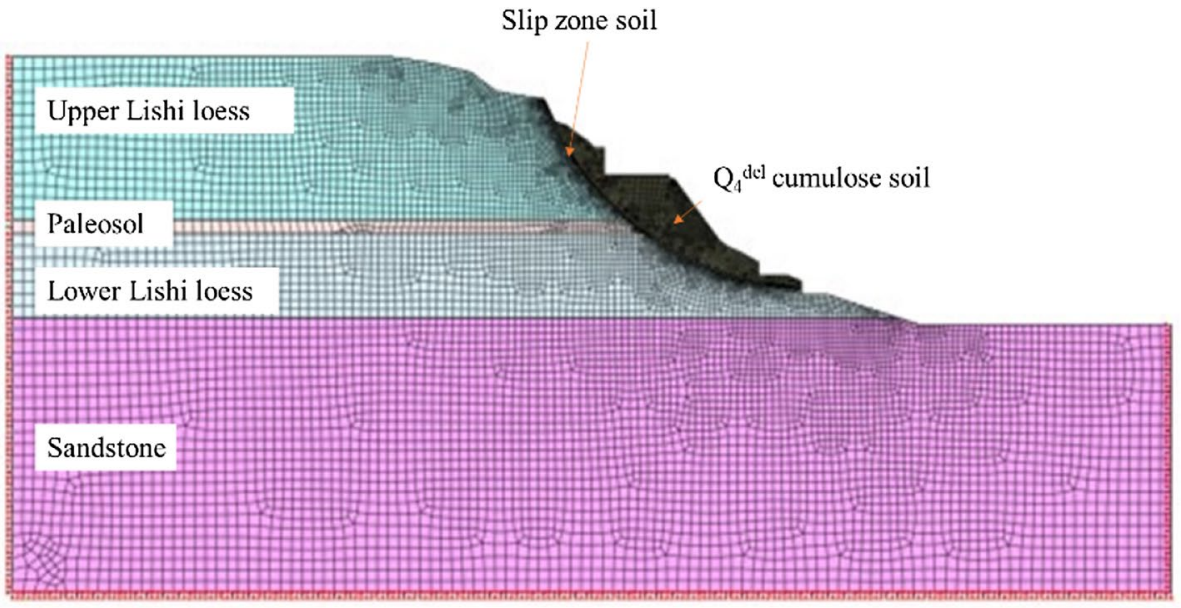

(a) Initial landslide condition

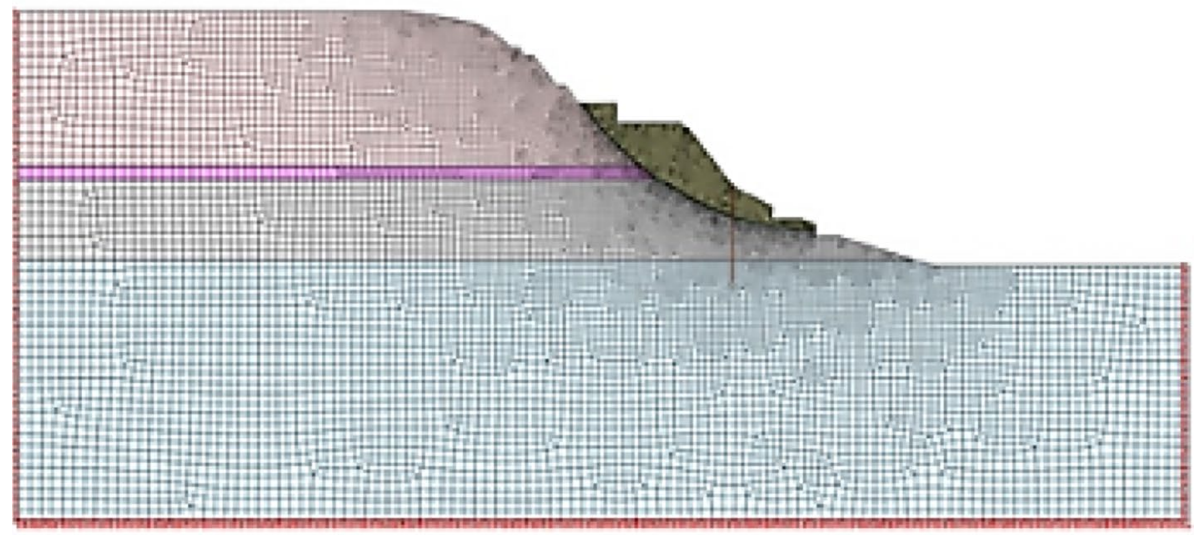

(b) Slope with anti-slide piles

Fig. 4 Generalized slope model and finite element mesh

probable; however, local collapse and/or caving was highly likely. The slope stability worsened during rainfall, which consequently could trigger slope failure. Adopting the combination of landslide mitigation measures of slope cutting and anti-slide piles, the SF values were 1.41 and 1.34 under the normal and storm conditions, respectively, indicating that the control scheme effectively improved the slope stability.

\subsection{Discussion of numerical results}

The numerical analysis provided insight into slope stability before and after treatment under normal and storm conditions. For example, the stress-strain distributions, displacement variations, soil-pile interactions, and tendencies of the slope stability could be evaluated effectively. Detailed discussions are presented in the following subsections. 
Table 1 Material properties for all parameters used for analyses

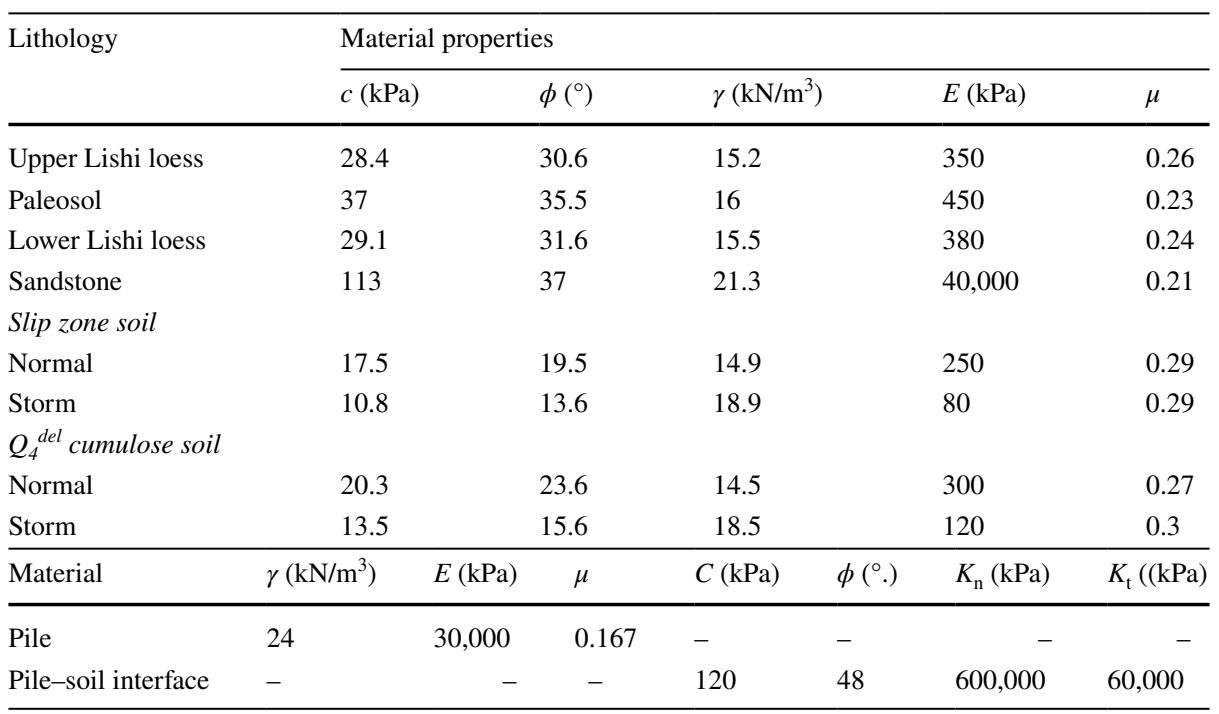

\subsubsection{Displacement}

Figure 5 illustrates the displacement variations in the $X$ - and $Y$-directions before and after the slope treatment under the normal and storm conditions. As indicated in Fig. 5, the maximum displacement in the $X$-direction of the initial slope occurred around the lower third of the slope (elevation of $870 \mathrm{~m}$ ) directly behind a retaining wall, regardless of the applied stress conditions. The maximum displacement in the Y-direction occurred somewhat lower (in front of the retaining wall) and exhibited substantially smaller magnitudes. For the treated slope, the maximum displacement in the $X$ - and $Y$-directions appeared to be larger than that of the initial slope because of the constraint associated with the anti-slide piles. However, all the slope displacements indicated uplifting behind the pile, indicating that the sliding thrust of the slope was effectively counterbalanced.

\subsubsection{Shear strain distributions}

The shear strain distributions for the slope under normal and storm conditions before and after landslide treatment are presented in Fig. 6. Similar to the results presented in Fig. 5, the shear strain distributions exhibited an identical trend from the toe of the slip plane to a location directly behind the anti-slide pile. The maximum shear strain of the treated slope also displayed a substantially smaller value than that of the initial slope, decreasing from 1.03 to 0.37 under storm conditions. As can be observed in the figure, the anti-slide pile apparently impeded the shear stress induced by the sliding mass and successfully maintained the overall slope in a stable state, particularly under storm conditions. 


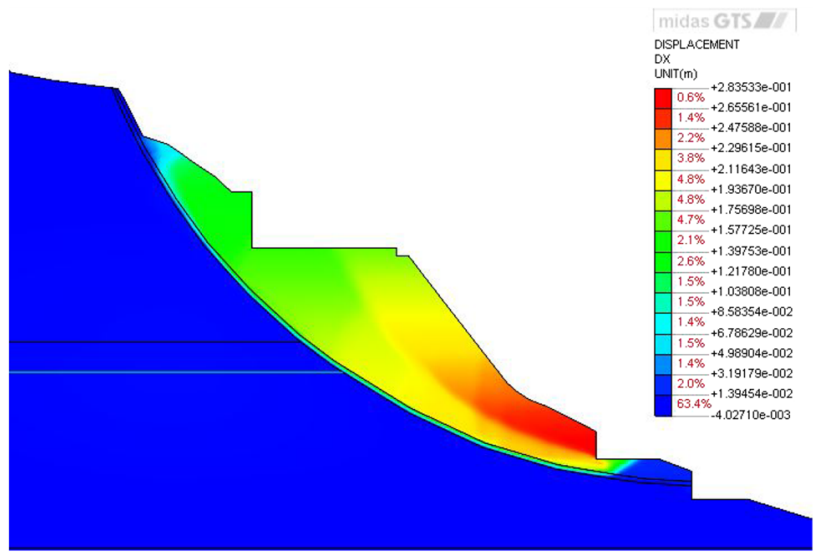

(a) Displacement contour in the X-direction for initial slope under normal condition

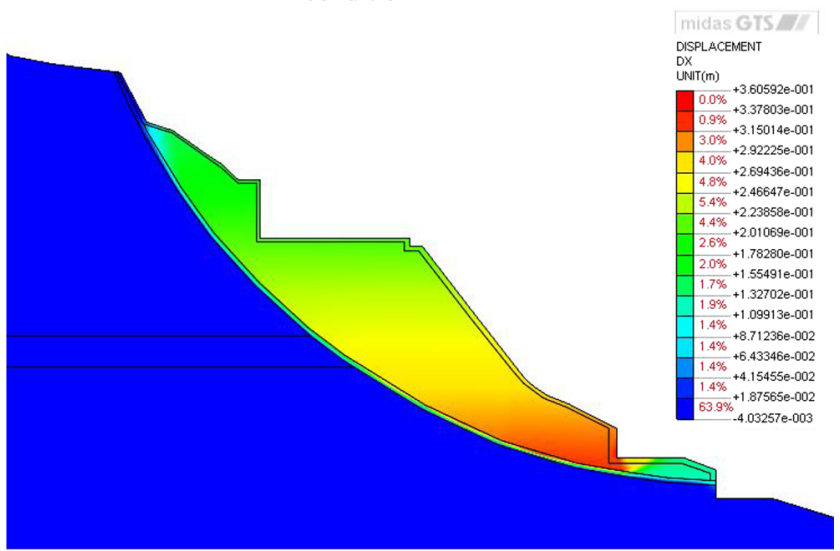

(b) Displacement contour in the X-direction for initial slope under storm condition

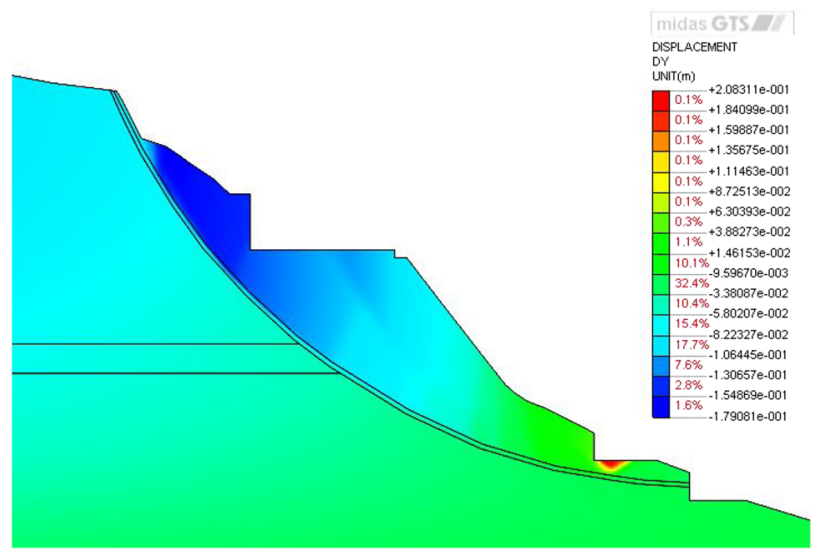

(c) Displacement contour in the Y-direction for initial slope under normal conditions

Fig. 5 Variations of displacement in $X$ and $Y$ directions before and after treatment under normal and storm conditions 


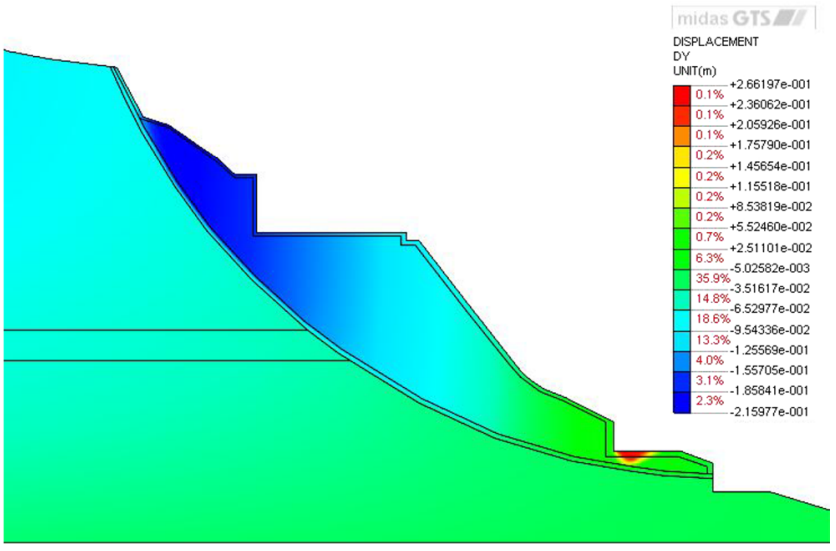

(d) Displacement contour in the Y- direction for initial slope under storm conditions

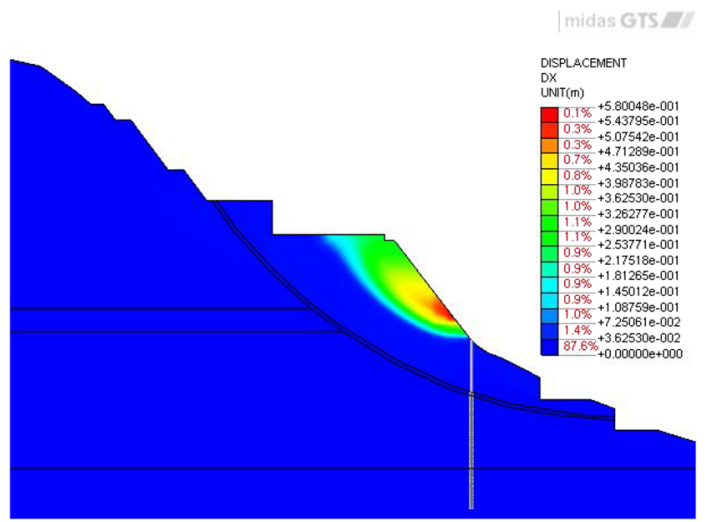

(e) Displacement contour in the X-direction for slope stabilized with piles under normal conditions

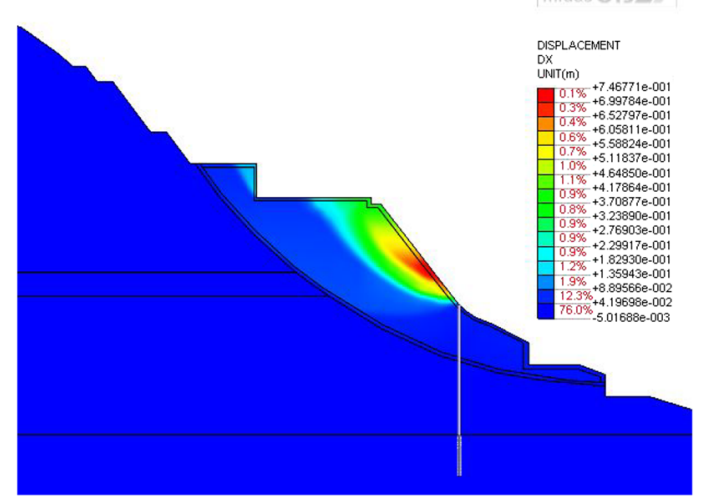

(f) Displacement contour in the X-direction for slope stabilized with piles under storm conditions

Fig. 5 (continued) 


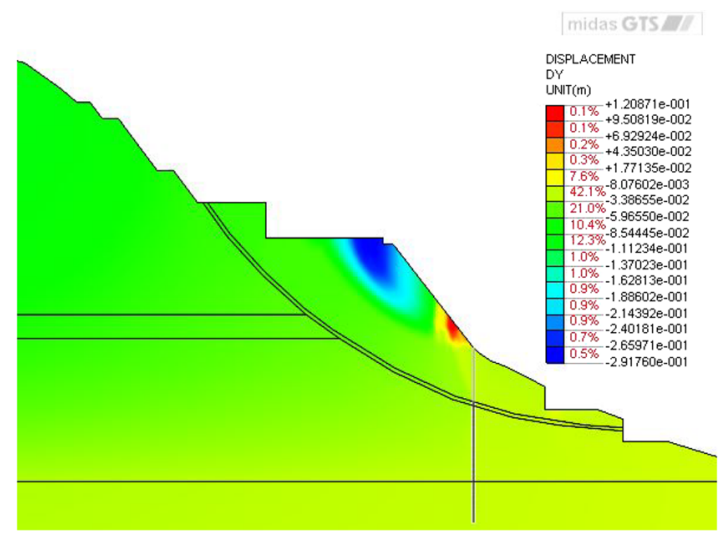

(g) Displacement contour in the Y- direction for slope stabilized with piles under normal conditions

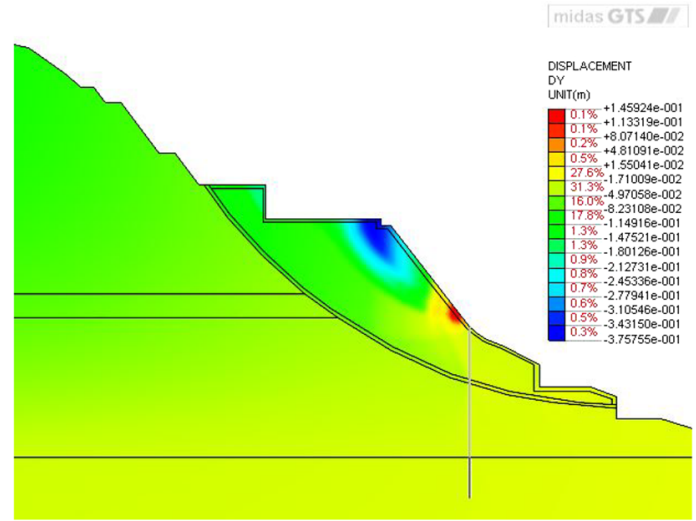

(h) Displacement contour in the Y- direction for slope stabilized with piles under storm conditions

Fig. 5 (continued)

\subsubsection{Stress variations}

Figure 7 illustrates the stress variations in the $X$ - and $Y$-directions for slopes under different conditions. The tensile stresses are indicated in black in the figure. For the analysis, the Midas GTS program assigned tensile stress as positive and compressive stress as negative. As illustrated in Fig. 7, both horizontal and vertical stresses developed along the rupture surface after slope failure was initiated. Under normal conditions, the tensile stress was mainly distributed in the upper and toe regions of the slip zone. However, under storm conditions, the region of tensile stress expanded along the entire rupture surface, resulting in the development of tension cracks and causing the slope to collapse. When the combination of cutting and anti-slide piles was adopted for stabilization, the rupture surface became a compressive zone, preventing the tension cracks from expanding and triggering extensive failure. Moreover, the tensile stress shifted upward to the middle of the slope behind the anti-slide pile, where a tensile stress concentration zone was formed. However, the maximum tensile stress of the treated slope was lower than that of the initial slope. An anti-slide pile was considered an elastic beam element. The stress acting on the pile resulted in an 


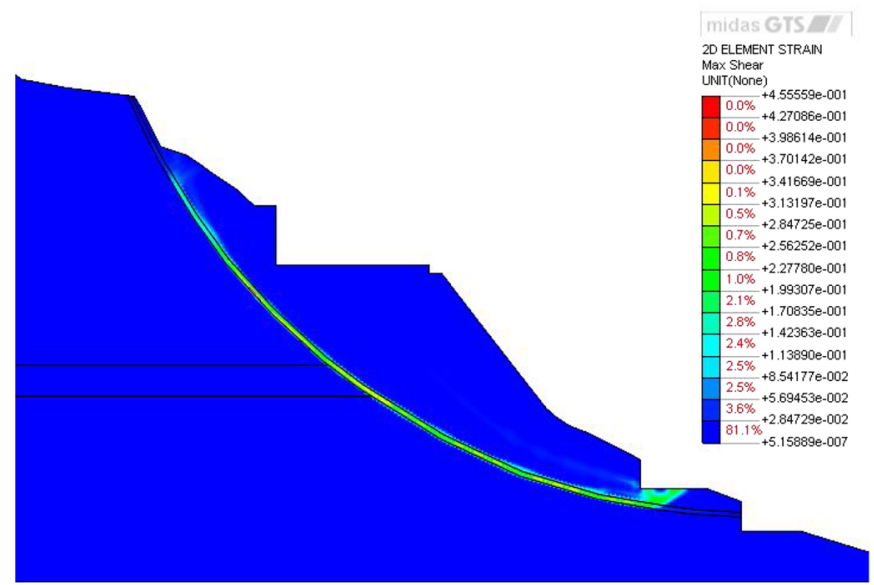

(a) Shear strain distribution for initial slope under normal conditions

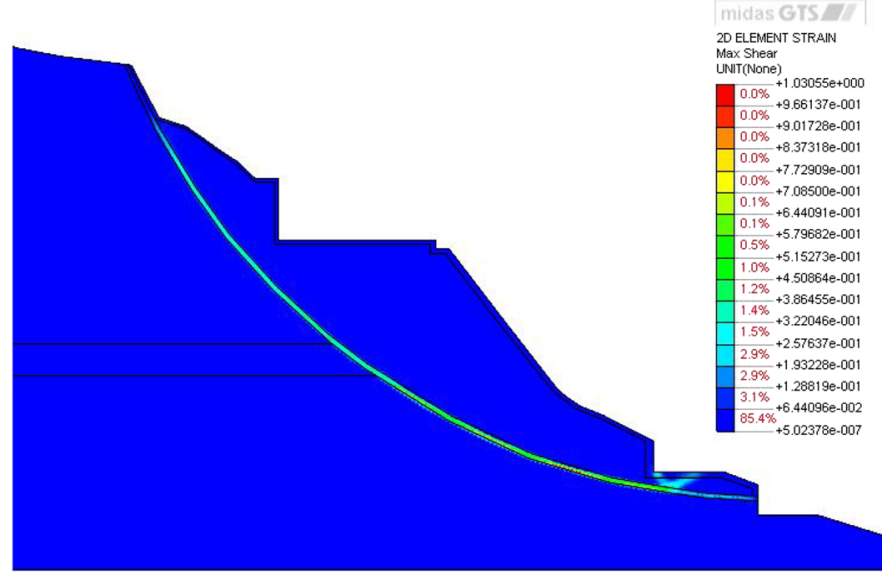

(b) Shear strain distribution for initial slope under storm conditions

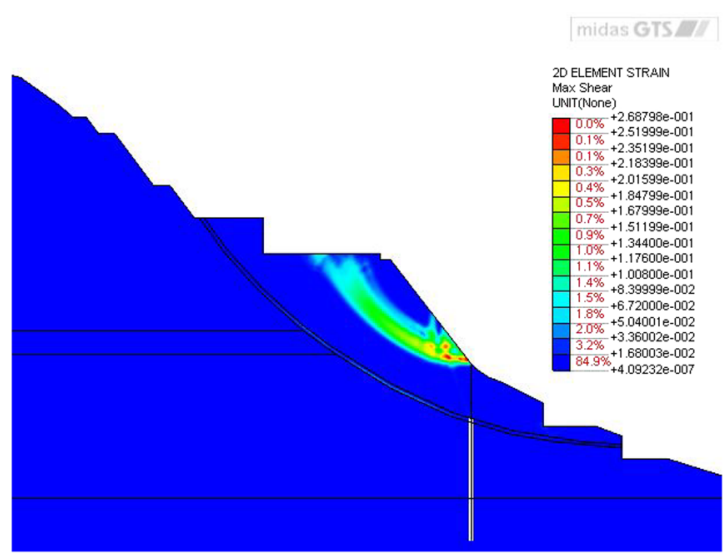

(c) Shear strain distribution for slope stabilized with anti-slide pile under normal condition

Fig. 6 Shear strain distribution for slope under normal and storm conditions before and after landslide treatment 


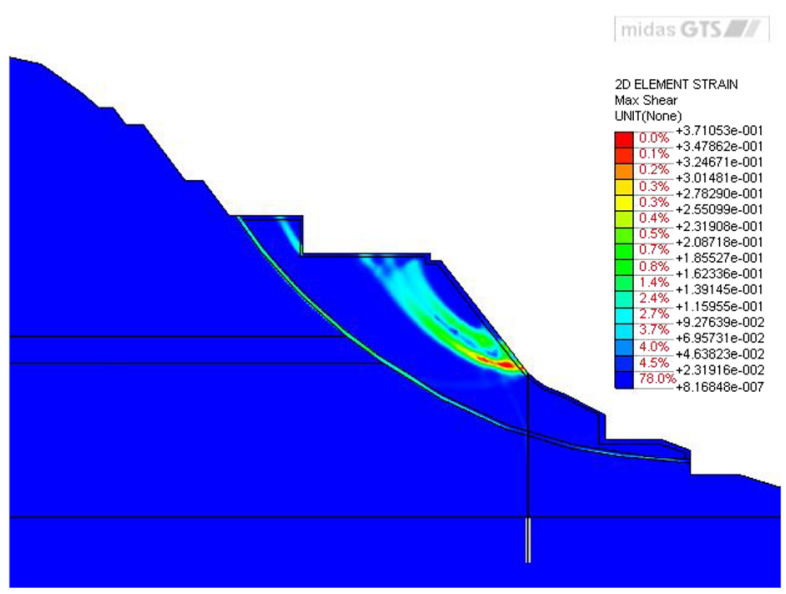

(d) Shear strain distribution for slope stabilized with anti-slide pile under storm condition

Fig. 6 (continued)

opposite reaction on the soil in a direction against the sliding thrust, thereby improving the slope stability.

\subsubsection{Comparison and validation of results}

Based on the monitoring data of the deep deformation collected with a borehole tiltmeter, Li et al. (2006) found that the deformation of the landslide, originating from the rupture zone, progressively and slowly accumulated from the bottom to the top. Most of the intraaggregate pores were saturated with water, even at the residual suction value. Xie (2004) successfully conducted field monitoring and a numerical simulation analysis to study the stress-strain relationships of a highly reinforced embankment. Based on previous experience, 150 equally spaced monitoring points were installed from the top to the bottom along the slip surface (Fig. 8). The distributions of the displacement, stress, and strain were collected, compared, and analyzed for all the applied conditions.

Figures 9 and 10 illustrate the monitored variations in displacement of the slide surface in the $X$ - and $Y$-directions for all the conditions analyzed. The maximum displacements obtained for the initial slope under storm conditions were 30 and $20 \mathrm{~cm}$ in the $X$ - and $Y$-directions, respectively. However, the deformation of the slide surface decreased sharply following treatment, dropping to 7 and $10 \mathrm{~cm}$ in the $X$ - and $Y$-directions, respectively, under heavy rainfall conditions. These results indicate that the anti-slide piles were effective and decreased the slope movement.

Figure 9 further indicates that the displacement of the initial slope before treatment exhibited a strong tendency to increase from the top to the toe of the slip surface. The displacement increment and rate of increase at the sliding surface at monitoring points 10-20, which were located on the upper platform of the slope, were quite large under normal conditions. Beyond the 20th monitoring point, the rate of increase decreased, and the displacements of the middle and lower parts of the slope maximized at monitoring points 100-110. Thereafter, the displacement decreased steadily to the toe of the slope, the sliding surface displacement decreased rapidly near monitoring point 130, and the displacement 


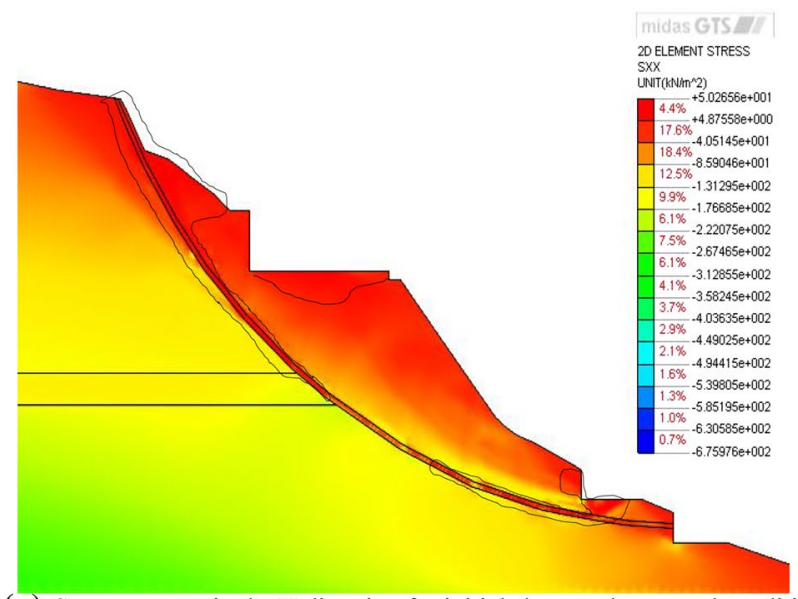

(a) Stress contour in the $\mathrm{X}$ direction for initial slope under normal condition

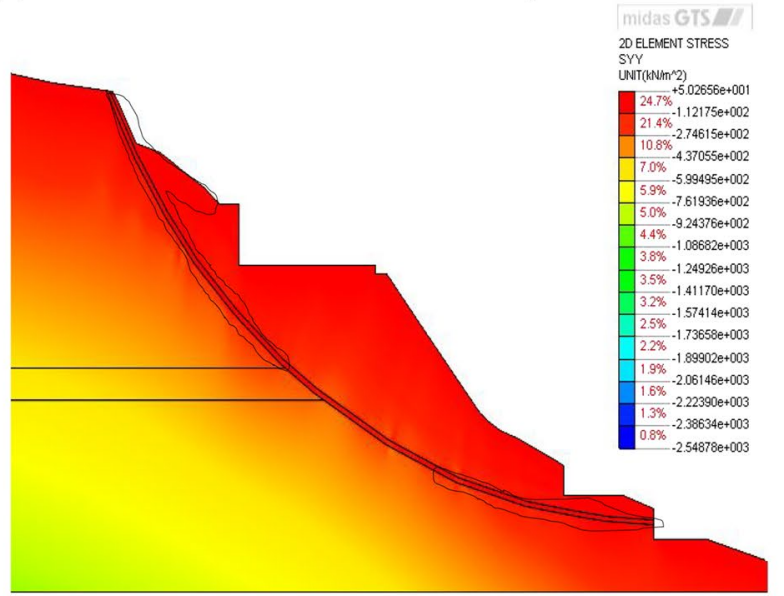

(b) Stress contour in the Y direction for initial slope under normal condition

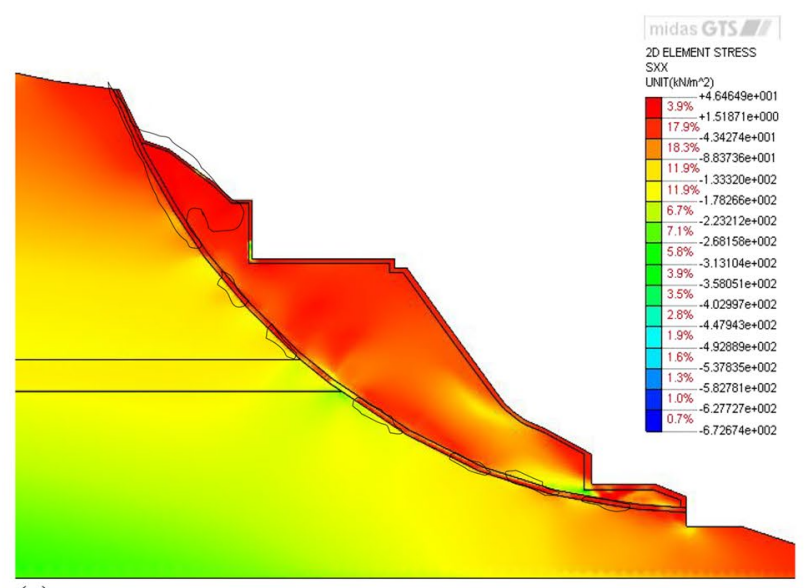

(c) Stress contour in the $\mathrm{X}$ direction for initial slope under storm condition

Fig. 7 Stress variations in $X$ and $Y$ directions for slope under normal and storm conditions before and after landslide treatment 


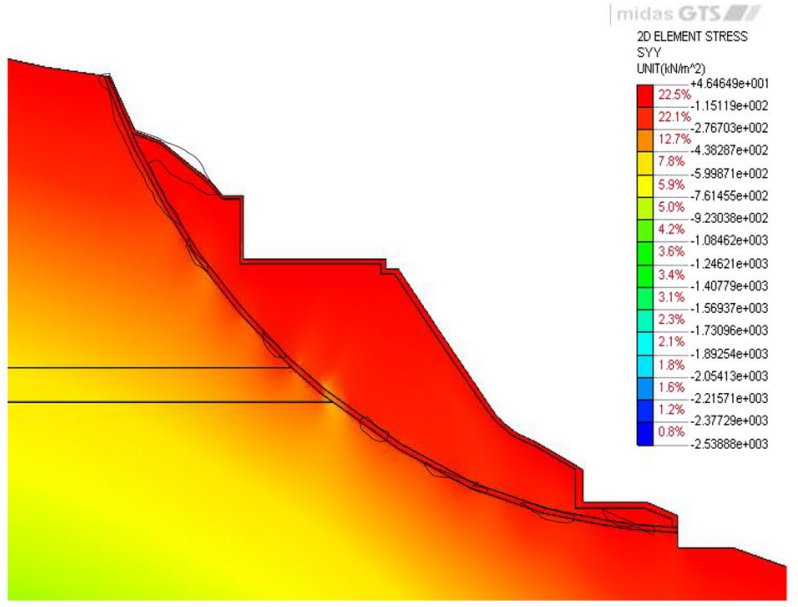

(d) Stress contour in the Y direction for initial slope under storm condition

| midas GTS

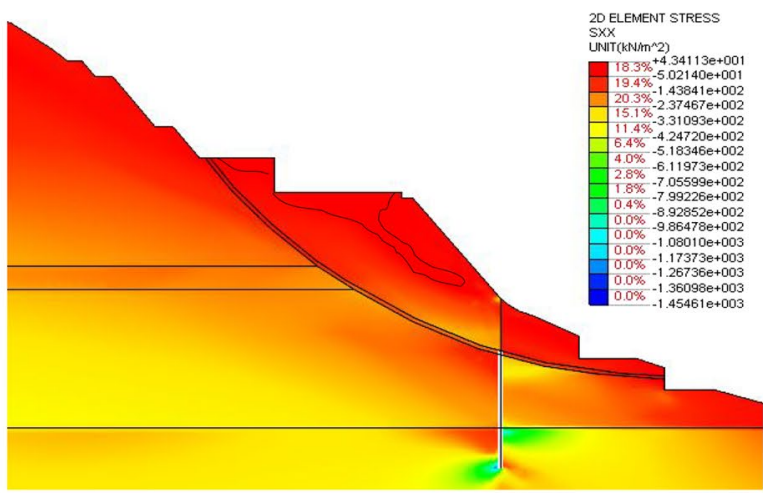

(e) Stress contour in the $\mathrm{X}$ direction for slope stabilized with anti-slide pile under normal condition

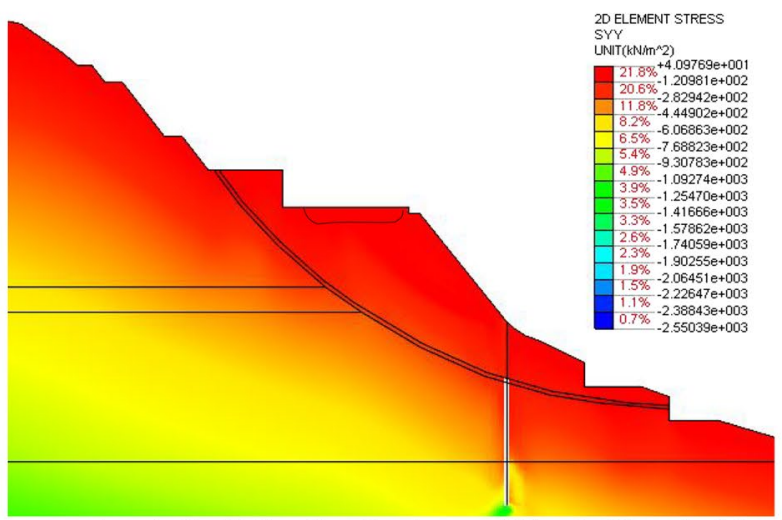

(f) Stress contour in the $\mathrm{Y}$ direction for slope stabilized with anti-slide pile under normal condition

Fig. 7 (continued) 


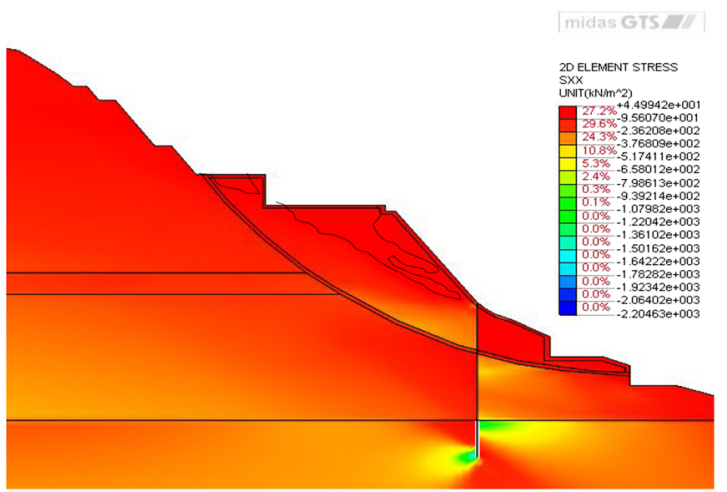

(g) Stress contour in the $\mathrm{X}$ direction for slope stabilized with anti-slide pile under storm condition

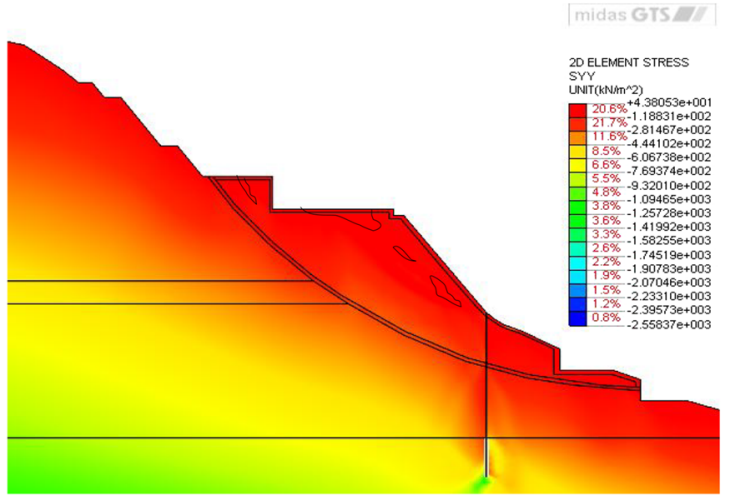

(h) Stress contour in the Y direction for slope stabilized with anti-slide pile under storm condition

Fig. 7 (continued)

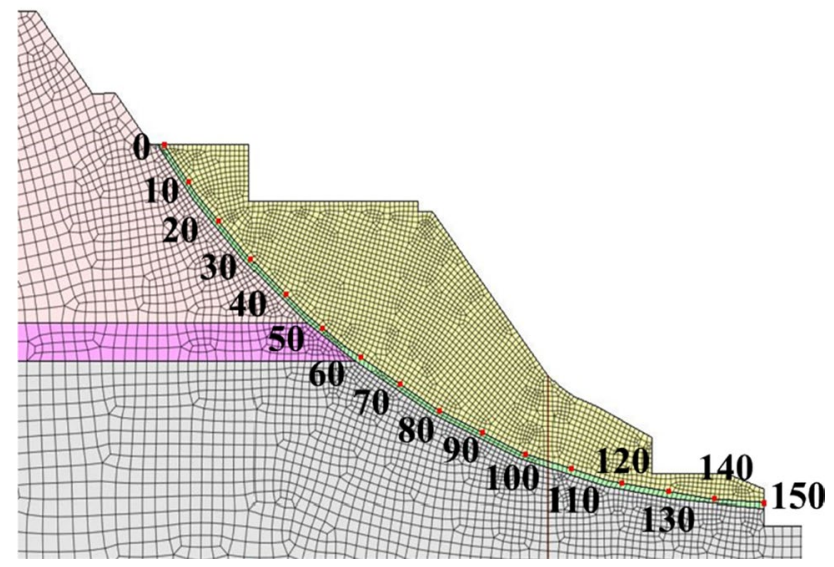

Fig. 8 Location of monitoring points 


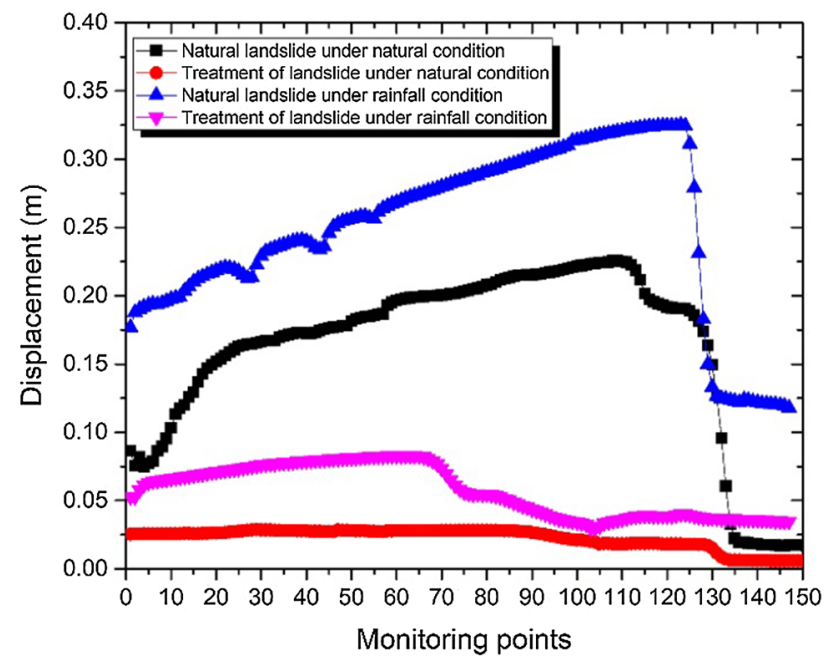

Fig. 9 Monitored displacement variations in $X$-direction for all applied analytical conditions

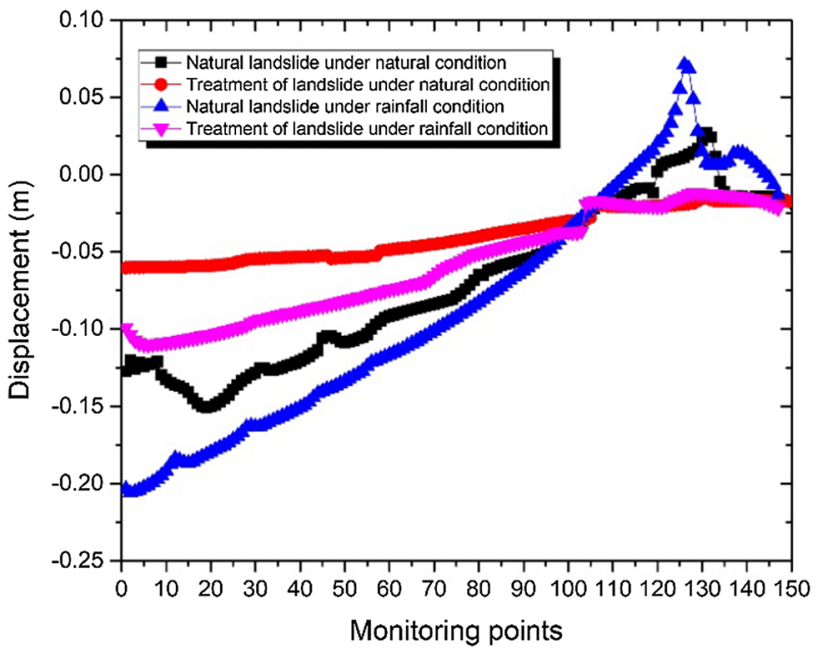

Fig. 10 Monitored displacement variations in $Y$-direction for all applied analytical conditions

at the toe of the slope was approximately $15 \mathrm{~cm}$. After the displacement at the end of the slope decreased to the minimum, it became stable at approximately $2 \mathrm{~cm}$. Following treatment, the displacement increment in the $X$-direction of the slope was approximately $2.5 \mathrm{~cm}$ under normal conditions. In the case of heavy rain, the displacements of the upper and central sliding surfaces of the slope exhibited a slight increase before the 70th monitoring point. However, the displacement of the middle part of the slope rapidly decreased to approximately $3.5 \mathrm{~cm}$ and tended to stabilize at the 70th monitoring point. The observations demonstrate that the sliding surface deformation gradually stabilized after treatment 
under normal conditions. Although several local deformations occurred in the slope under storm conditions, the slope appeared to be stable.

Figure 10 illustrates the monitored displacement variations in the $Y$-direction for all the applied conditions. The maximum displacement observed in the $Y$-direction under normal conditions was approximately $15 \mathrm{~cm}$, which was located at the head of the slope near the 20th monitoring point. The maximum displacement observed in the $Y$-direction increased to approximately $20 \mathrm{~cm}$ under storm conditions, decreasing gradually toward the toe along the sliding surface. The tendency of these variations indicated that the sliding apparently caused the displaced material of the slope to move upward at the toe near monitoring point 120. The upward movement worsened under storm conditions, and the total displacement increased to $10 \mathrm{~cm}$ near monitoring point 110 . The displacement decreased significantly and the upward movement was terminated after the installation of the anti-slide piles. The maximum displacement of the landslide under normal and storm conditions decreased to 5 and $10 \mathrm{~cm}$, respectively. The displacement gradually decreased and finally converged to approximately $1 \mathrm{~cm}$ at the toe (monitoring points 110-150). Such results also indicate that the anti-slide piles provided sufficient support to stabilize the damaged slope. Figure 11 illustrates the monitored shear strain of the slope before and after treatment. Although the trend varied to a certain degree, it was similar to those indicated in Fig. 9. The variations in the shear strain on the slip surface differed significantly because of the conditions encountered. For the initial conditions, the shear strain of the landslide increased and then decreased, with its maximum value of approximately $18 \%$ observed near monitoring point 15. The upper part of the slope indicated that the shear deformation variations were highly correlated with the slope terrain. The shear strain then exhibited minor variations until it reached monitoring point 130 , located near the toe of the slope, where it rapidly decreased to an insignificant value.

The applied storm conditions immediately caused the shear strain to increase up to 0.20 , which remained nearly constant along the slip surface. The shear strain then exhibited a rapid increase from monitoring point 100, located in the middle and lower parts of the slope, and reached the maximum value of approximately 0.36 near monitoring point 130

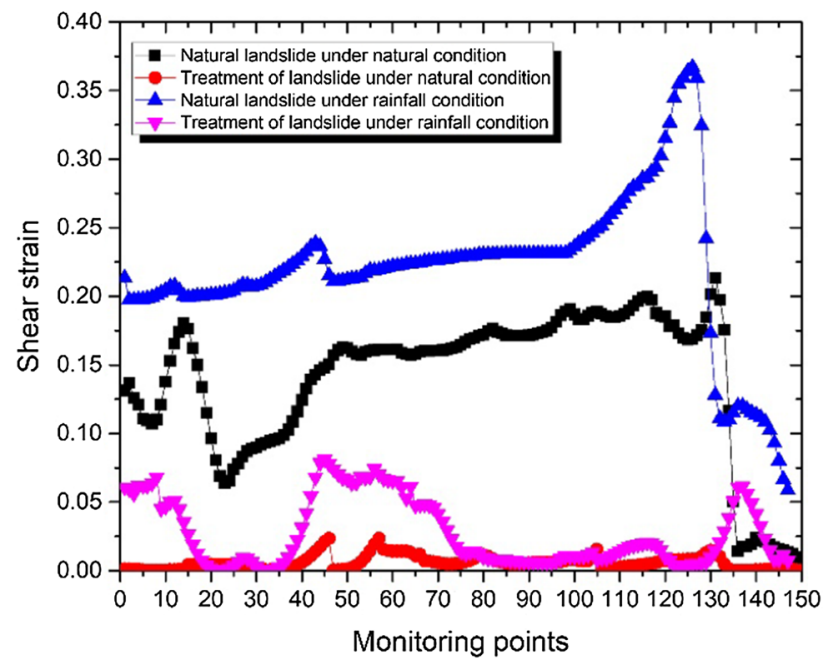

Fig. 11 Monitored shear strain variations in $X$-direction for all applied analytical conditions 
at the toe of the slope. As mentioned previously, rainfall is a common triggering factor for landslides in most loess areas. Numerous cavities, fissures, and cracks have been formed by erosion in these areas, allowing a large amount of rainwater to infiltrate; therefore, immediately after shearing begins, the pore water pressure increases sharply, triggering a landslide.

Based on the analysis performed in this study, the anti-slide piles installed at this location for stabilization were found to be effective. As illustrated in Fig. 11, this arrangement successfully achieved the purpose of the treatment. The shear deformation of the slope became insignificant under normal conditions, and the maximum shear strain was reduced to approximately 0.06 , even under storm conditions.

Figures 12 and 13 illustrate the monitored stress distributions in the $X$ - and $Y$-directions of the slope for all applied conditions. Although the trends varied, the compressive stress generally increased along the sliding surface before treatment of the slope. A tension effect occurred, and the compressive stress gradually decreased in the middle to lower parts of the slope (monitoring points 60-110). Tension eventually controlled the slope, while transverse ridges, tensile cracks, and upward ground movement were observed at the toe. The incremental changes in the stress under the storm conditions occurred more rapidly than those associated with the normal conditions. The findings agree well with those presented in Fig. 11. The installation of the anti-slide piles immediately transformed the tension stress into compressive stress, as indicated at monitoring point 100 in Fig. 13. Thus, the stabilization of the anti-slide piles was effective for improving the slope stability.

The combination of cutting and anti-slide piles basically eliminated the tensile stress in the $X$ - and $Y$-directions and caused the compressive stress to increase along the slide surface. This placed the slope in a balanced state of compressive stress distribution, which obviously enhanced its stability. The displacement and shear strain of the slide surface were significantly reduced owing to the resulting stabilization. The plastic deformation of the slide surface was effectively controlled, which indicates that the overall stability of the landslide was greatly improved. The quantitative analysis of the displacement and stress

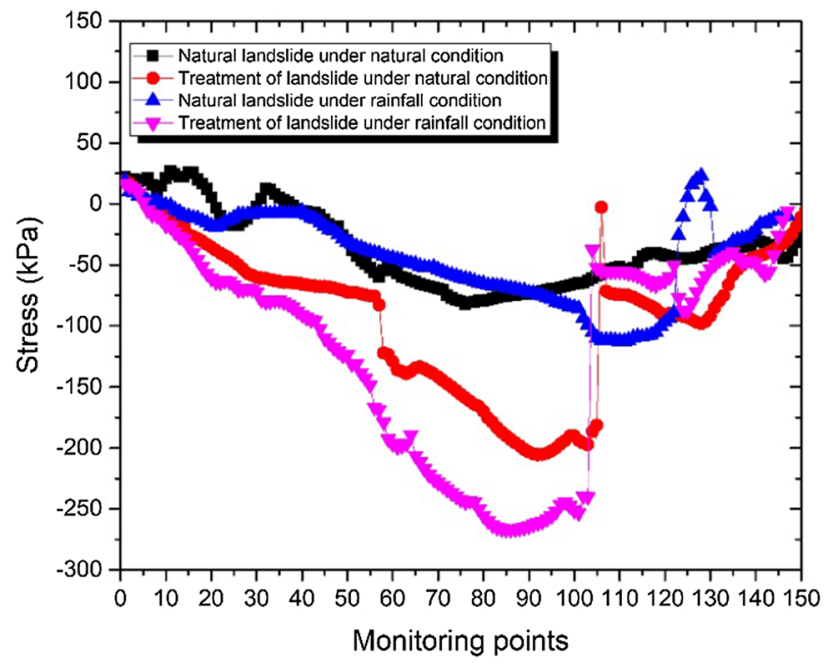

Fig. 12 Monitored stress variations in $X$-direction for all applied analytical conditions 


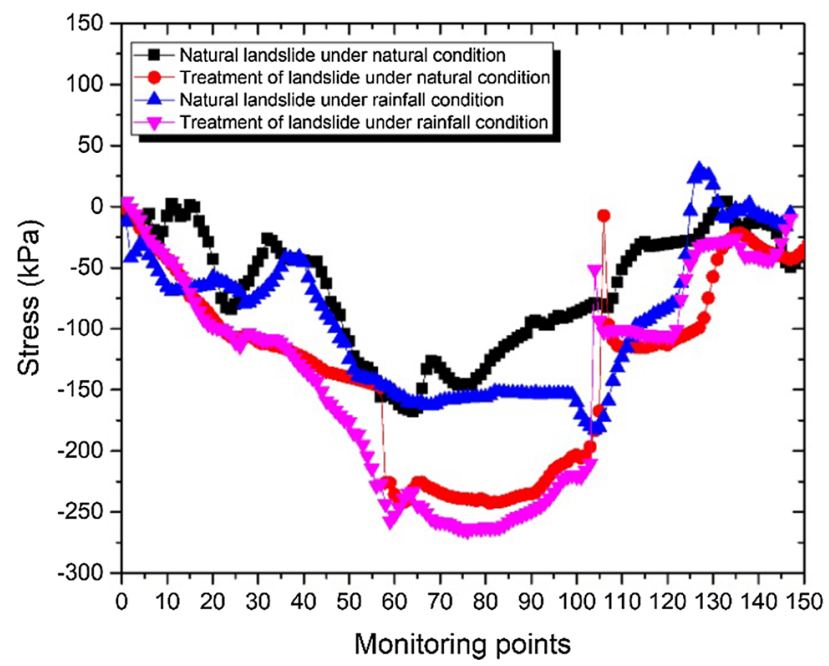

Fig. 13 Monitored stress variations in $Y$-direction for all applied analytical conditions

distributions at 150 monitoring points along the slide surface proved that the use of antislide piles was effective and beneficial for the remediation of the loess landslide.

\section{Conclusions}

Based on the results of the analyses conducted in this study, the following conclusions can be drawn:

1. The Zhonglou Mountain landslide is a loess landslide that exhibits top extension and bottom shearing deformation. The landslide is mainly controlled by tectonic fractures and gravity-induced tensile fractures. The contact surface of the loess and paleosol is saturated, resulting in the formation of a soft sliding zone due to precipitation, which causes the landslide to slide under the action of gravity and rainfall.

2. The Zhonglou Mountain loess landslide was extensively studied using finite element numerical simulation. Prior to stabilization, the SF values of the initial slope were derived based on a strength reduction method and ranged from 1.06 to 0.74 for the normal and storm conditions. The slope collapsed because of heavy rainfall, indicating that the simulations agreed very well with the actual site observations.

3. According to the landslide shear strain distributions under normal and storm conditions, the plastic shear strain region under storm conditions was greater than that under normal conditions along the sliding surface and basically extended along the entire sliding surface. The maximum shear strain zone shifted down from the middle and upper parts of the landslide to the location of shear cracking. The position of the shear crack of the landslide under normal conditions also shifted down along the sliding surface under the circumstance of heavy rain.

4. The combination of cutting and anti-slide piles effectively reduced the amount of landslide displacement under both normal and storm conditions. The shear strain distributions were also adequately controlled by shifting the strain upward to the location 
directly behind the anti-slide piles, indicating that the slope stability was successfully improved by the treatment.

The results of this study clearly indicate that the stabilization successfully reversed the distributions of tensile stress to compressive conditions, eliminated the tension cracks, limited the amount of displacement, controlled the plastic deformation along the sliding surface, and thereby significantly improved the overall slope stability. The stabilization of the landslide was completed in 2016 based on the proposed remediation scheme developed in this research. The slope surface was well protected by vegetation and an effective drainage system. The slope has remained stable and become an area of eco-friendly development since the completion of remediation. This study reveals the landslide mechanism of typical loess mudstone through on-site investigation and numerical simulation, which can provide a theoretical reference for the prevention and control of similar landslides in loess regions.

Loess landslides occur frequently on the Loess Plateau and seriously threaten people's lives and property. They also affect the construction of hydropower, transportation, industrial, and agricultural facilities following the strategy of western development in China. The deformation mechanism of loess landslides is controlled by many factors. The potential instability of loess is determined by its typical characteristics, such as fragmented topography, loess macropore structure, vertical joint development, and water sensitivity. Dynamic external environmental factors such as earthquakes, rainfall, and human engineering activities continuously contribute to slope instability.

At present, experts in China and abroad have carried out two-dimensional and threedimensional numerical simulations of landslides as well as various studies on macroscopic and microscopic soil characteristics, greatly expanding the understanding of this topic. However, as a common geological hazard, the uncertainty and unpredictability of landslides are still great challenges to address. In future research, it is necessary to not only clarify the fundamental deformation mechanism of landslides but also provide a scientific basis for landslide prediction. At the same time, effective protective measures should be taken to reduce the occurrence of landslides. Notably, landslide control measures should be selected according to the local conditions, and landslide prevention methods should not be generalized.

Acknowledgements Sincere appreciation is extended to the anonymous reviewers and editors for their thoughtful review comments and suggestions, which have significantly improved this revised version of our manuscript.

Funding This study was financially supported by funding from the National Natural Science Foundation of China (41772323; 41972292), the International Key Scientific and Technological Cooperation and Exchange Program in Shaanxi Province, China (2019KW-02), the National Key Research and Development Program of China (2017YFD0800501), and the Geological Survey Project of the China Geological Survey (DD20189270).

\section{Compliance with ethical standards}

Conflict of interest The authors declare that they have no conflicts of interest related to this work. The authors declare that they do not have any commercial or associative interest that represents a conflict of interest in connection with the work submitted. Sincerely, Wanli Xie is a Professor of State Key Laboratory of Continental Dynamics, Department of Geology, Northwest University, Xi'an, Shaanxi, China, 710069. E-mail: xiewanli@nwu.edu.cn. 
Open Access This article is licensed under a Creative Commons Attribution 4.0 International License, which permits use, sharing, adaptation, distribution and reproduction in any medium or format, as long as you give appropriate credit to the original author(s) and the source, provide a link to the Creative Commons licence, and indicate if changes were made. The images or other third party material in this article are included in the article's Creative Commons licence, unless indicated otherwise in a credit line to the material. If material is not included in the article's Creative Commons licence and your intended use is not permitted by statutory regulation or exceeds the permitted use, you will need to obtain permission directly from the copyright holder. To view a copy of this licence, visit http://creativecommons.org/licenses/by/4.0/.

\section{References}

Adhikary DP, Dyskin AV (2007) Modelling of progressive and instantaneous failures of foliated rock slopes. Rock Mech Rock Eng 40(4):349-362. https://doi.org/10.1007/s00603-006-0085-8

Agam MW, Hashim MHM, Murad MI, Zabidi H (2016) Slope sensitivity analysis using spencer's method in comparison with general limit equilibrium method. Procedia Chem 19:651-658. https:// doi.org/10.1016/j.proche.2016.03.066

Alemdag S, Kaya A, Karadag M, Gurocak Z, Bulut F (2015) Utilization of the limit equilibrium and finite element methods for the stability analysis of the slope debris: an example of the Kalebasi District (NE Turkey). J Afr Earth Sci 106:134-146. https://doi.org/10.1016/j.jafrearsci.2015.03.010

Ardalan H, Ashour M (2013) Analysis of landslides and slopes stabilized using row of piles. Deep Foundation Institute, Hawthorne

Chen Y, Xue Q, He X, Zhang S, Wang P, Song C (2019a) Stability analysis on veneer cover system for landfill considering the effect of internal seeper. Eng Geol 252:99-109. https://doi.org/10.1016/j. enggeo.2019.02.024

Chen Y, Xue Q, He X, Zhang S, Wang P, Song C (2019b) Stability analysis on veneer cover system for landfill considering the effect of internal seeper. Eng Geol. https://doi.org/10.1016/j.engge o.2019.02.024

Crawford MM, Bryson LS, Woolery EW, Wang Z (2019a) Long-term landslide monitoring using soilwater relationships and electrical data to estimate suction stress. Eng Geol 251:146-157. https:// doi.org/10.1016/j.enggeo.2019.02.015

Crawford MM, Bryson LS, Woolery EW, Wang Z (2019b) Long-term landslide monitoring using soil-water relationships and electrical data to estimate suction stress. Eng Geol. https://doi. org/10.1016/j.enggeo.2019.02.015

Derbyshire E (2001) Geological hazards in loess terrain, with particular reference to the loess regions of China. Earth Sci Rev 54(1-3):231-260. https://doi.org/10.1016/S0012-8252(01)00050-2

Dijkstra TA, Rogers CDF, Smalley IJ, Derbyshire E, Li YJ, Meng XM (1994) The loess of north-central China: geotechnical properties and their relation to slope stability. Eng Geol 36(3-4):153-171. https://doi.org/10.1016/0013-7952(94)90001-9

Feng JL, Tao ZG, Li DJ (2017) Evaluation of slope stability by the in situ monitoring data combined with the finite-discrete element method. Procedia Eng 191:568-574. https://doi.org/10.1016/j.proen g.2017.05.219

Hailong G, Xie W, Xu Y (2015) Evaluation of the partition of Chang'an district landslide disaster prone based on fuzzy judgment method. J Anhui Agric Sci 43(17):155-156 (in Chinese)

Li Y (2018) A review of shear and tensile strengths of the Malan Loess in China. Eng Geol 236:4-10. https://doi.org/10.1016/j.enggeo.2017.02.023

Li D, Li Y, Zhang M (2006) Analysis of starting deformation of landslide belt of accumulation body. Chin J Rock Mech Eng 25(S2):3879-3884 (in Chinese)

Li P, Vanapalli S, Li T (2016) Review of collapse triggering mechanism of collapsible soils due to wetting. J Rock Mech Geotech 8(2):256-274. https://doi.org/10.1016/j.jrmge.2015.12.002

Li Y, Zhang T, Zhang Y, Xu Q (2018) Geometrical appearance and spatial arrangement of structural blocks of the Malan loess in NW China: implications for the formation of loess columns. J Asian Earth Sci 158:18-28. https://doi.org/10.1016/j.jseaes.2018.02.007

Li P, Xie W, Pak RYS, Vanapalli SK (2019) Microstructural evolution of loess soils from the Loess Plateau of China. CATENA 173:276-288. https://doi.org/10.1016/j.catena.2018.10.006

Liu SY, Shao LT, Li HJ (2015) Slope stability analysis using the limit equilibrium method and two finite element methods. Comput Geotech 63:291-298. https://doi.org/10.1016/j.compgeo.2014.10.008 
Peng D, Xu Q, Qi X, Fan X, Dong X, Li S, Ju Y (2016) Study on early recognition of loess landslides based on field investigation. Int J Geohazards Environ 2(2):32-52. https://doi.org/10.15273/ ijge.2016.02.006

Qiu H, Cui P, Hu S, Liu Q, Wang Y, Gao Y, Deng M (2016) Size-frequency distribution of landslides in different landforms on the Loess Plateau of Northern Shaanxi. Earth Sci 41(2):343-350

Wei Z-L, Lu Q, Sun H-Y, Shang Y-Q (2019) Estimating the rainfall threshold of a deep-seated landslide by integrating models for predicting the groundwater level and stability analysis of the slope. Eng Geol 253:14-26. https://doi.org/10.1016/j.enggeo.2019.02.026

Xie W (2004) Study on deformation and stability of high filled reinforced embankment in Loess Area. Northwestern University, Evanston (in Chinese)

Xie W-L, Li P, Vanapalli SK, Wang J-D (2018a) Prediction of the wetting-induced collapse behaviour using the soil-water characteristic curve. J Asian Earth Sci 151:259-268. https://doi.org/10.1016/j.jseae s.2017.11.009

Xie W-L, Li P, Zhang M-S, Cheng T-E, Wang Y (2018b) Collapse behavior and microstructural evolution of loess soils from the Loess Plateau of China. J Mt Sci Eng 15(8):1642-1657. https://doi.org/10.1007/ s11629-018-5006-2

Xu L, Dai FC, Tham LG, Tu XB, Min H, Zhou YF, Wu CX, Xu K (2011) Field testing of irrigation effects on the stability of a cliff edge in loess, North-west China. Eng Geol 120(1-4):10-17. https://doi. org/10.1016/j.enggeo.2011.03.007

Xu L, Coop MR, Zhang M, Wang G (2018) The mechanics of a saturated silty loess and implications for landslides. Eng Geol 236:29-42. https://doi.org/10.1016/j.enggeo.2017.02.021

Zhang F, Wang G, Kamai T, Chen W, Zhang D, Yang J (2013) Undrained shear behavior of loess saturated with different concentrations of sodium chloride solution. Eng Geol 155:69-79. https://doi. org/10.1016/j.enggeo.2012.12.018

Zhang G, Hu Y, Wang L (2015) Behaviour and mechanism of failure process of soil slopes. Environ Earth Sci 73(4):1701-1713. https://doi.org/10.1007/s12665-014-3522-0

Zheng Y, Chen C, Liu T, Zhang H, Xia K, Liu F (2018) Study on the mechanisms of flexural toppling failure in anti-inclined rock slopes using numerical and limit equilibrium models. Eng Geol 237:116-128. https://doi.org/10.1016/j.enggeo.2018.02.006

Zhuang J, Peng J, Wang G, Javed I, Wang Y, Li W (2018) Distribution and characteristics of landslide in Loess Plateau: a case study in Shaanxi province. Eng Geol 236:89-96. https://doi.org/10.1016/j.engge o.2017.03.001

Publisher's Note Springer Nature remains neutral with regard to jurisdictional claims in published maps and institutional affiliations.

\section{Affiliations}

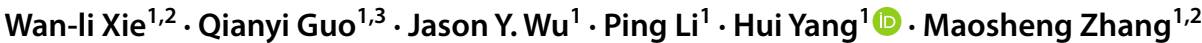

Wan-li Xie

xiewanli@nwu.edu.cn

Jason Y. Wu

jasonwu@chu.edu.tw

Ping Li

1p19881028@163.com

\section{Maosheng Zhang}

xazms@126.com

1 State Key Laboratory of Continental Dynamics, Department of Geology, Northwest University, Xi' an 710069, Shaanxi, China

2 Key Laboratory for Geo-Hazards in Loess Area, Ministry of Land and Resources, Xi' an Center of China Geological Survey, Xi'an 710054, China

3 Shaanxi Hydrogeology Engineering Geology and Environment Geology Survey Center, Xi'an 710068, Shaanxi, China 